\title{
Self-care for the researcher: Dark tourism in Varanasi, India
}

\begin{abstract}
Dark tourism is a popular niche of tourism that allows tourists to come into close proximity with death, atrocity, and the macabre, and therefore has the potential to be an emotional and even traumatic encounter for tourists. While this context has inspired tourism researchers to investigate dark tourists' motivations, as well as the marketing and representation of dark tourism sites, we have yet to attend to its implications for the researcher. This paper analyzes the emotional experiences and aftermath of fieldwork at the cremation grounds of Varanasi, India, which involved working closely with tourists, Doms, and Aghoris by focusing on the relations of reflexivity, positionality, and emotionality. As a result, we suggest a number of reflexive and self-care practices to be put into place so as to attend to the researchers' emotional well-being in the fieldwork process.
\end{abstract}

Keywords: self-care, reflexivity, positionality, emotionality, dark tourism, Varanasi

\section{Introduction}

Dark tourism allows tourists to experience the unthinkable from a relatively safe position, either removed temporally from the event or having the ability to leave the site after only a short duration (see for example Ashworth, 2002; Buda, et al; 2014). This genre of tourism includes 
such “dark" places as: graveyards, prisons, and sites of conflict, tragedy, atrocity, and disaster. In conducting research with dark tourists, the researcher takes care to attend to the potential emotional triggers of the site and its story. In fact, research ethics approval often requires specific explanations of how the researcher has prepared for such challenges. Yet, in all this necessary concern for dark tourists as subjects situated in emotionally sensitive spaces, the researcher has been overlooked (with the exception of Buda, et al. 2014). Indeed, even as Buda et al. (2014), in studying tourists in the "conflict zone" of Jordan, writes herself into the experiences of pain and shock, there is no reflection on the impacts of these experiences on the researcher herself. As Kleinman and Copp (1993, p.2) more broadly observe, "classic ethnographies either omit a researcher's emotions or relegate them to a preface or appendix". In preparing for the emotionality of tourists' experiences, most researchers do not attend to their own potential needs and emotional care. In fact, self-care strategies remain absent from qualitative methodologies across disciplines (see Rager, 2005; Arber, 2008). Thus, what is missing from dark tourism chronicles is how the exposure to (both short and long-term) and embodied experiences at sites of death can have lingering emotional and psychological consequences for the researcher, as well as communication about effective self-care strategies that can be employed throughout the research process or episodically as needed.

While the notion of "self-care" has gained considerable popularity outside academia, with organizations such as the Self Care Forum institutionalizing a broad spectrum of self-care awareness, attempts to ground these practices within tourism research remain unrealized. Defined broadly, self-care "represents the range of behaviour undertaken by individuals to 
promote or restore their health" (Dean, 1989, p.117). While grounded in the health sciences, as this definition suggests, self-care has been taken up by psychology and sociology as well with particular interest in secondary trauma related to health care and social work professionals whose work with chronic and/or terminal illnesses and victims of abuse can also become emotional burdens (see Lee-Treweek,2000; Rager 2005; Killian, 2007; Newell \& MacNeil, 2010). Importantly, notes Dean (1989), self-care is active, autonomous participation in one's physical or emotional health.

This paper aims to situate the role of self-care in dark tourism research by examining its relationality to reflexivity, positionality, and emotionality, with particular attention to the implications for the researcher exposed to death and the macabre during fieldwork. The vignettes discussed are based on experiences of the first author while carrying out fieldwork at Varanasi, India, which involved working closely with tourists, Doms, and Aghoris at its cremation grounds. While the broader research project was concerned with tourists' motivations and experiences of death and landscape in this region, as well as examining the interactions of tourists with Doms and Aghoris in their spiritual space, the focus here is on the researcher. Using the researcher as the subject of enquiry, through reflexive practice post-fieldwork assisted by the second author, demonstrates dark tourism research as an emotion-laden process that extends beyond the research participants to affect the researcher as well. In analyzing the fieldwork experiences of the first author at the cremation grounds of Varanasi, we identified a number of themes that demonstrate the relationality of positionality and emotionality to reflexivity, including: role negotiation, gender dynamics, and (reverse) cultural shock. Thus, we suggest a 
number of reflexivity activities and self-care strategies that can be put into practice so as to attend to the researcher throughout the dark tourism fieldwork process, and which could be useful in other areas of tourism-related work that engages the researcher in emotionally laden and potentially traumatic sites.

\section{Reflexivity, positionality, and emotionality}

Reflexivity and positionality are crucial to qualitative research, as together these perspectives assist in understanding the role of the researcher and the relations of the researcher to her/his participants (see DeLuca \& Maddox, 2015). As such, they also prove essential to self-care and the related strategies employed by the researcher, particularly when attention is paid to the emotionality of the research context and potential outcomes and consequences of the research experience. Thus, reflexivity is an ongoing practice through which the researcher can critically approach positionality and emotionality across the research process (pre- through post-fieldwork) and interrogate knowledge construction (see Ateljevic, et al., 2005).

"Reflexivity is the capacity to reflect upon one's actions and values during the research, when producing data and writing accounts, and to view the beliefs we hold in the same way that we view the beliefs of others" (Arber, 2006, p. 147). As such, it is often seen as a challenging component of emotionally sensitive research, but is necessary to the maintenance of integrity, credibility, and reliability in the process of interpreting participants' experiences (see Kleinman 
\& Copp, 1993; Coffey, 1999; Rowling, 1999; Hubbard et al., 2001; Pellatt, 2003; Moser, 2008). That "information is always mediated through the Self" further supports the importance of reflexivity in qualitative inquiry, as the researcher must repeatedly interrogate and take account of one's own biases, perceptions, and ideologies, as well as embodied experiences, so as to assess positionality (DeLuca \& Maddox, 2015, p. 286). Indeed, reflexivity is a continuous practice of both rigorous qualitative research but also researcher self-care that takes attends to positionality and emotionality.

Just as the participants' experiences are framed in social-cultural contexts, so too are those of the researcher. "Positionality is thus determined by where one stands in relation to "the other"" (Merriam et al., 2001, p. 411). Positionality represents a space in which objectivism and subjectivism meet, and according to Freire (2000, p.50), "the two exist in a 'dialectic' relationship". Ethnographic fieldwork relies upon the interactions, relations, and situatedness of the researcher and the researched. Positionality represents a space of interaction between the researcher and participants wherein the identities of both parties influence not just each other but also the research process (Dewalt \& Dewalt, 2002; Wax, 1979), as positionality can include role negotiation, insider/outsider relationships, gender, race, class, and other socio-cultural (perceived) differences. Further, positionality can trigger emotional responses for both the researcher and the participant.

According to Denzin (1984), emotionality lies at the intersection of the person and society. Although the word "emotion" is highly ambiguous (Hochschild, 1983; Burkitt, 1997; Wharton, 
1999), we work from the notion that emotions are responses, which are physiological in origin, varied and complex, and interwoven with one's value system. They are culturally defined and socially constrained (Rosenberg, 1990, p. 3-12). Emotions accompany fieldwork just as they do any other experience in one's life. Pre-fieldwork finds most researchers in states of excitement and anxiety as one prepares for data collection. Emotions generated in the field can include loneliness, frustration, despair, unease, uncertainty, disappointment, anger, self-pity, failure, grief, and inadequacy (Rabinow, 1977) to more positive experiences of relief, curiosity, and enthusiasm. Jaggar (1989, p. 29) states that "just as observation directs, shapes and partially defines emotion, so too emotion directs, shapes and even partially defines observation."

While we can observe "major shifts in social science research, emotionality is still constructed in opposition to rationality and professionalism” (Wincup, 2001, p. 19; see also Blackman, 2007; Williamson, 1996; Jagger, 1989; Ateljevic, et al., 2005). Emotions have been seen as a problem to overcome in order to do good research (Ellis, 1991; Cohen, 2013), with calls for a detached stance during participatory research by adhering to the belief that emotions are a barrier to rigorous research, and that the job of a researcher is to "get opinions not have them" (Oakley, 1981, p. 35). Although researchers are often encouraged to control or suppress their emotions, this does not mean that emotions are not present. Further, it is likely that hidden emotions may nevertheless affect the research process (Jagger, 1989). Yet, the tendency to avoid any discussion of the emotional impact the research process may have on the researcher continues (Wolf, 1996; Young \& Lee, 1996), despite acknowledgement that such research may cause emotional pain or trauma to those involved (Rowling, 1999; Gilbert, 2001; Johnson \& Clarke, 2003). 
This suggests the critical role of reflexivity as a technique. Goleman (1995) asserts that awareness of emotions benefits the research process, and similarly, others (Kleinman \& Copp, 1993; Carter \& Delamont, 1996; Widdowfield, 2000; Hubbard et al., 2001; Holland, 2007) have called for transparency with respect to feelings, emotions, and struggles that emerge before, during, and after fieldwork. Reflecting critically on one's own emotions, behavior, and role in the field enables us "to understand the parallels between our experience as researchers and that of those we study" (Lee-Treweek, 2000, p. 128). Sensory, embodied, and emotive aspects of the fieldwork encounter, previously marginalized in favor of an emphasis on observation alone, are now seen as viable avenues in the process of knowledge generation (Thurnell-Read, 2011). Certain qualitative researchers, especially feminist, (although even within the feminist tradition, the inclusion of emotions is debated (see Maynard \& Purvis, 1994; Gilbert, 2001)) have maintained that reflexivity in research is required to consider the role of social processes and values and their interaction with the researcher's background and social stance. Further, reflexivity has been central to the "critical turn" in tourism studies, as it deconstructs the supposed neutrality of positivism while also allowing the researcher to write themselves into their projects (Ateljevic et al., 2005; Feighery, 2006).

Despite this greater attention to the role of emotions in the research process, many continue to write of their experiences of emotional pain, trauma, guilt, depression, and other lingering effects (see Rager, 2005; Arber, 2006; DeLuca \& Maddox, 2015). This suggests that while more researchers are incorporating critical perspectives on their emotionality into post-fieldwork 
analysis, including reflexivity and positionality techniques, practical strategies for self-care and researcher well-being have yet to be institutionalized into pre-fieldwork. Indeed, DeLuca and Maddox (2015, p.296) contend that continuing to ignore the need for self-care strategies "creates dishonesty in our work as it is crucial that we acknowledge the unsettling and troublesome aspects of fieldwork."

\section{Researching death and tourism in Varanasi}

According to Hindu belief, Varanasi is the holiest of all cities in India and it attracts scores of domestic and foreign tourists alike. Situated on the banks of the Ganga River, it is known as the “Great Cremation Ground" (Eck, 1983, p. 30), "Kashi, the luminous", "the ancient Crossing”, the "City of death", and the "microcosm of the universe" (Parry, 1994, p. 11). It is believed that people who die here automatically attain moksha (salvation). The elevated riverfront is public commons space for worship. Cremations, wherein ancient historical traditions that sustain cultural memories, beliefs, and values, are enacted and re-enacted every day. Crucial to this ceremonial space are Doms and Aghoris. Doms are keepers of the sacred fire and control access to the cremation grounds, while Aghoris are a group of ascetics who practice at the ghats. Thus, death and death rituals form a central concern in the cultural and religious system of Varanasi, and although formally labelled as a Hindu pilgrimage destination, the city and its spaces of death attracts tourists from around the world (Figure 1). 


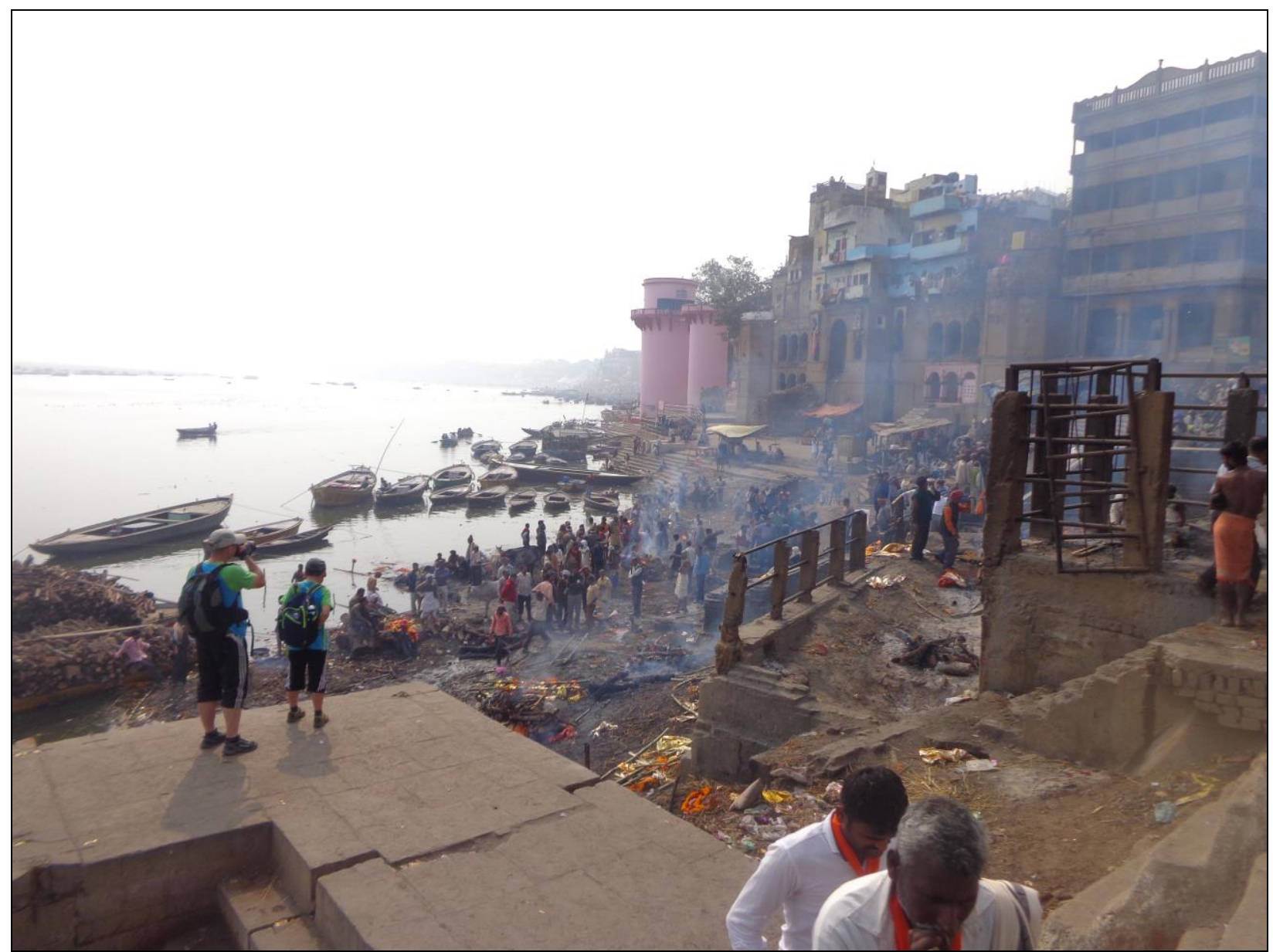

Figure 1 - Tourists observe the cremation grounds at Manikarnika Ghat. Photo by Author 1.

This paper examines the fieldwork experiences of the first author carried out during May-August 2015 and December 2015- March 2016. That research was focused on tourists' experiences of death and landscape in this region, and thus this paper is the result of reflexive inquiry of author 1's personal experiences through fieldnotes and analysis of her memories. The analysis was initiated by author 1 through self-reflexive inquiry to generate personal written accounts, then 
followed up by collaborative analysis by both authors and focused on themes related to positionality and emotionality - role negotiation, gender, class, and cultural shock, specifically. As such, the "I" in this paper is referencing author 1, as the use of the first person is crucial to the telling of the emotional experience of the researcher, while "we" refers to the collaborative aspects of this work.

As an Indian woman, born and raised in the country, I felt confident in my understanding of Varanasi as space of cultural and religious significance. Further, having lived in the USA for almost 5 years, developing research on the psychological role of death anxiety in touristic experiences of the cremation grounds at Varanasi, India, I had become comfortable discussing and analyzing the nuances of death rituals associated with this place. Moreover, I had taken a number of qualitative methodology courses and I had completed ethics review at my university before entering the field. Therefore, it came as a surprise when I struggled to cope up with the emotional engagement that was required to conduct fieldwork at the cremation grounds. To begin to understand the disparity of my fieldwork preparedness and fieldwork experience, I initiated a reflexivity activity by asking myself questions regarding my positionality in the field, which also further developed the method of "researcher as research instrument" (see Pezalla, et al., 2012). This resulted in a series of longer written accounts, which included excerpts of fieldnotes and recounts of memories with retrospective interpretations, and was then followed by collaborative analysis with author 2 of the materials produced. What results are a series of vignettes interwoven with analysis that attends to the key themes of role negotiation, gender, class, and cultural shock. Together, these accounts uncover the shortcomings of pre-fieldwork 
training, strategies that assisted in overcoming emotional stress, guilt, intense empathy, and trauma, as well as recommendations for researchers (seasoned and novice) entering into emotionally-laden research.

\section{Challenges of participant observation and role negotiation}

In participant observation, the researcher is the prime and direct instrument of data collection, as it involves the immersion of the researcher in the situation, and thus offers more potential for emotional factors to impinge upon the research process (Hockey, 1996). Further, participant observation relies on the researcher's conscious efforts to understand the processes of transformation that occur by being in the field (Baszanger \& Dodier, 1997). Immersed in the cremation grounds of Varanasi for 5 months, the heightened viscerality of the ceremonial space was overwhelming at times. Traversing my way through the funeral pyres on a daily basis, I was surrounded by the smell of human flesh with smoke engulfing my face and clouding my view, while numbing my sense of smell and making me feel nauseated. The embodied sensation of the space along with its ceremonial richness fed my own anxieties. There were moments I found myself consumed with a sudden surge of emotions towards my own loved ones. As these emotions grew, it became challenging to maintain an analytical perspective towards observation, and I needed to take regular breaks from the cremation ground to recover. With distance I was better able to reflect on the experience and the ways that constant exposure to death had altered my own perception towards life and death. It enabled me to better empathize with interviewees, as I attempted to engage my own emotional experience in analyzing tourists' perceptions of the space. However, this also led to further ethical dilemmas of participant observation. It was a 
challenge to be a passive and non-intrusive observer of someone's death and not feel loss and pain for the deceased's grieving family. In the case of observing death rituals, I often experienced feelings of guilt such that I decided to not approach mourners in an effort to not disturb their privacy.

This heightened emotional experience also influenced interactions with interviewees, and in fact, were common topics of conversation with tourists in particular. For example, a few tourists elaborated on their feelings of guilt over visiting the cremation grounds or the feeling of strangeness they experienced while witnessing the rituals. One tourist expressed her disgust at the public handling of dead bodies, adding that she had not anticipated that the rituals would affect her in a negative manner. So while emotional awareness can assist in empathizing with participants, researchers may often encounter situations in which their personal feelings are at odds with their professional role. I encountered this while interviewing an Aghori whose narrative included details of how he collected human skulls for his rituals and how he indulged in necrophagy (feeding on corpses or carrion) as part of an initiatory rite. While reflecting on my conflicting feelings, I realized the significance of these differing positional perspectives. So while I was prepared for the emotional dissonance of Varanasi tourists, I was taken aback by my own emotional conflict. In researching Varanasi, I thought I was prepared to encounter Aghoris and their practices. Yet, the embodied experience of the space in addition to hearing personal, detailed accounts from them challenged my ability to be objective. This was further challenged by the differing ways tourists and Doms and Aghoris perceived me as an insider/outsider to this place. 


\section{Insider-outsider dilemmas}

Hindu death rituals are performed publicly by Doms (a class of lower social standing in Hindu society) who control all the activities at the cremation ground (selling wood, carrying the dead, arranging flowers, and other items required for death rituals). Personally, my position in the social hierarchy as someone who belongs to an upper caste in Hindu society was never a matter of importance to me. At the cremation ground, however, this was a barrier to access. The Doms are an insulated community and to probe into their inner dynamics my identity and positionality proved a challenge. I was a cultural "insider" but a social “outsider”. In fact, as Ganga and Scott (2006, para 2) have pointed out, “interviewing within one's own 'cultural' community —as an insider - affords the researcher a degree of social proximity that, paradoxically, increases awareness amongst both researcher and participant of the social divisions that exist between them". Insider/outsider positions are porous (Ganga \& Scott, 2006), and this association created very different interactions with tourists.

While I expected that my position as an Indian would aid me in connecting especially well with the Indian ritual performers (although it did not), I also wrongfully assumed that this identity would require me to make special efforts to connect with the international tourists. Such an expectation seemed reasonable, as research has also suggested that people tend to gravitate toward those with whom they share some level of commonality (Fries-Britt \& Turner, 2002). Yet, as was made evident during interviews with American tourists, my residency in the US created a familiarity while my Indianness suggested I had particular insights I could share. 
Indeed, tourists from the US were more responsive and willing to talk when I told them that I was an academic in their country. They spoke to me as if they had met someone with whom they were familiar, and therefore, were quite open about their views and experiences. The ritual performers, on the other hand, took their own time and opened up rather slowly. A possible interpretation is that they expected a fellow Indian to know some of these rituals, and moreover, it may have been unusual for them to see an Indian woman at the cremation grounds taking an assertive role. My identity as an academic in a different country also added to their suspicion and initial hesitation. Clearly, the participants were mediated by my perceived positionality as insider/outsider.

\section{Gender}

"Gendered spaces" are those that a specific community invests with gendered meanings, where sex-differentiated practices occur, and which are strategically used to form an identity that is often an asymmetrical relation of power (see Domosh, 1998). While considering asymmetries in power and identity relations, scholars have used spatial dimensions that theorize the differences between men and women and have mostly associated these asymmetries to men's greater power and social status (see Bourdieu, 1977, p. 214). The cremation grounds at Varanasi are socially constructed in a way that restricts the entry of women. There are no formal rules or regulations that say this but access to the death rituals and participation (except in a few cases) is normatively limited for women. Therefore, the process of going to the cremation grounds, observing the death rituals, and interviewing tourists and ritual performers, was beset with challenges. These included feelings of self-consciousness, as well as awkward and even 
embarrassing moments of walking into a swarm of a hundred male funeral workers and attempting to negotiate and re-negotiate space with them.

In order to blend in at the funeral grounds and avoid overly attracting the predominant male gaze, I gave considerable thought to how I should dress in the field. I chose to dress in plain, traditional Indian clothes as opposed to my usual Western attire. Although it was not uncommon for the ritual performers to see tourists in all sorts of Western gear, there was an unspoken and silent expectation of me, as a woman of Indian origin, to respect the culture and tradition. The cremation ground at Varanasi was clearly an unchartered territory for a female researcher and despite my visible 'Indian-ness', my gender contributed to my positionality as an outsider to the ritual performers.

\section{Culture shock}

The anthropologist Oberg (1960) coined the term "culture shock" to explain the anxiety that results from losing all one's familiar signs and symbols of social interaction. He identified six components: (1) psychological strain; (2) sense of loss and feelings of deprivation; (3) feelings of rejection by the new culture; (4) confusion in role expectation, values, and feelings; (5) surprise and anxiety at realization of cultural differences; (6) feelings of impotence at inability to cope with or integrate into the new environment. There are multiple factors involved in culture shock, such as purpose of visit (holiday, gap year, business travel, business relocation), nationality, prior travel experiences, expectations, intimacy of experience, and social network support (Stewart \& Legatt, 1998). The concept "reverse culture shock" is similar to culture shock, but the adjustment 
process focuses on the difficulties of re-adapting and re-adjusting to one's own home culture after one has sojourned or lived in another cultural environment. According to Gullahorn and Gullahorn (1963), the main difference between reverse culture shock and culture shock lies in the expectations of the sojourners. Those who stay away from their home for a prolonged period often expect to return to an unchanged home as unchanged individuals. While culture shock is more commonly discussed in relation to tourists' experiences, my experience with "reverse culture shock" in India, is further evidence of the challenge that researchers might face when they find themselves conducting research into emotionally charged spaces of their "home" countries.

At Varanasi, there were moments when I felt that the beliefs and practices of my own religion, Hinduism, were alien to me. I started my fieldwork with a general idea of the death rituals and the Aghori way of life, but during the course of interaction I realized that I was ignorant of several aspects of my own religion and culture. The animated manner in which the Aghoris described their rituals during the interviews made me feel like a stranger to my own culture. Although I was aware of the sect before I began my fieldwork, the direct interactions with them brought a strange feeling of being detached from my religious and cultural roots. Death is inseparable from the city of Varanasi and the constant exposure to it made me relentlessly aware of the frailty of human life. The cremation grounds are located at the riverbank, locally known as the 'ghats', so due to logistical convenience I had decided to stay in a hotel which was located in the nearby area. I could hear processions and chanting of people carrying the dead even at night which made it impossible for me to take a break and dissociate myself temporarily from death. 
Amidst all this, as I struggled with thoughts and feelings about death and the meaning of life, I was also sure that my field research experience in Varanasi opened me spiritually to the origin of my culture, religion, and social identity. Thus, I carried the experience of this "reverse cultural shock" with me back to my current "home" in the States, where I again had to re-adjust to daily life away from the constant presence of death and spirituality.

\section{Trauma and post-fieldwork emotionality}

According to Sword (1999), fieldwork can be an intense and isolating experience and the impacts emotionally draining (Carter \& Delamont, 1996; Hubbard et al., 2001; Pellatt, 2003; Rager, 2005). Thus, being honest about one's own feelings “makes explicit how our stories are context bound and strengthens one's integrity as a researcher" (Sword, 1999, p. 277). Once fieldwork is complete, engaging with emotional a/effects that arise out of continued exposure to death can be traumatic, and reliving those experiences through transcribing, analyzing, and writing can be equally distressing. Hochschild (1983) refers to the "human costs" of emotional labor, from things like "'burnout" to feeling "phony", 'guilt", and "self blame". Researchers of death and atrocity are likely to be exposed, in embodied ways, to the pain and suffering of their participants, which can give them a heightened sense of their own mortality and vulnerability (Dickson-Swift et al., 2007; Rager, 2005). For example, during an interview with a tourist in which I asked about her perception of death, I found myself weeping out of empathy for her, because her views on death were deeply rooted in her mourning the recent death of her husband. I would be lying if I denied that her personal narrative did not affect my own emotions concerning life and death, grief, and even marriage. My empathy for this interviewee and her 
narrative did not remain in Varanasi, nor did it slip away into my fieldnotes, but I brought that memory back with me as a personal experience of this place. As a researcher, then, I relive this shared experience whenever I return to that transcript in the analysis of interview data.

\section{Attending to the self in dark tourism research}

While Arber (2008) suggests self-identifying the status position of the researcher in the research context aids credibility and reliability, the positionality of the researcher has been underexplored in dark tourism scholarship. Yet, the emotionally charged spaces of dark tourism are prime examples of potential researcher/researched positionality differentials, for example: a white researcher studying slavery heritage, a German researcher assessing tourism at concentration camps, an American researcher studying tourism at the 9/11 memorial, or a researcher from a developed country analyzing slum tourism. Further, Behar (1996) contends that when studying emotionally sensitive topics, we become "vulnerable observers"; we are affected by what we witness. Reflexivity is increasingly adopted in tourism studies as a means to interrogate the role of the researcher in the generation of knowledge (see Ateljevic, et al., 2005; Feighery, 2006). Of course, while reflexivity does aid in bringing awareness to asymmetrical and potentially exploitive field relationships, it cannot remove them (England, 1994, p.86). Nevertheless, employing reflexivity throughout the research process can help to prepare the researcher by encouraging questions, such as, “am I prepared to take on another's full humanity and to explore and unveil my own?” (Tillmann-Healy and Kiesinger, 2001, p.101), but also assist in identifying 
and working through emotionally challenging experiences while still in the field.

Self-care requires active, autonomous participation in one's physical and/or emotional health (see Dean, 1989). For the researcher, this begins by understanding the value of reflexivity as an ongoing practice that attends to the researcher's experiences of positionality and emotionality at the field site and in the construction of knowledge. While not all dark tourism presents such challenges to power/identity/role differentials, the sensitive nature of most dark tourism attractions does suggest the value of reflexivity exercises and the potential need for self-care strategies. Indeed, the encounters of Author 1 at Varanasi provide evidence for the ways even the self-assured, well-prepared researcher may find oneself ill-equipped to manage the emotionality of experiences while in the field. Thus, reflexivity exercises should begin before the fieldwork process. Engaging with questions about the researcher's positionality, what emotional reactions are expected from oneself and one's research participants, and familiarity with self-care strategies will help to minimize and mitigate emotional trauma. Reflexivity practices will also help the researcher to assess their own needs and responses to self-care exercises, as Killian (2008) observes there are no exact, prescriptive coping strategies that can attend to all individuals. The following are among the more common self-care strategies, which we suggest be further incorporated into qualitative methodology courses, texts, training, and compliance measures. In particular, in addition to students learning methodology techniques (interviewing skills, observation techniques, focus groups coordination, etc.), it is crucial for students to practice reflexivity, learn the symptoms of emotional fatigue, and even work through practical scenarios for responding to emotional and psychological stress in the field (see Newell \& 
MacNeil, 2010). Further, for example, university research compliance measures should not only focus on the research participants, the mode of data collection, and other data protection measures but also on the researcher and her/his familiarity with self-care strategies. Of course, some research ethics review boards are beginning to attend the implications of research for the researcher as well as the research subjects, this is often pushed to the background.

\section{Journaling}

While keeping fieldnotes is a necessary part of qualitative data collection, journaling can be a useful companion exercise that turns attention to the self. It is the act of recording one's thoughts and feelings as they happen or retrospectively (Rager, 2005). Thus, reflexivity is at the heart of journaling. It assists in recognizing the ways the researcher is being/has been changed by the research process (see Kleinman \& Copp, 1993; Baszanger \& Dodier, 1997; Arber, 2006), and as such demonstrates the active, autonomous engagement with one's emotional health that is central to self-care. "[R]eflexivity is much more than mere 'looking', [... [it] must also recognize the macro and micro forces which underpin the production of tourism knowledge, and acknowledge our interaction with and responsibilities to the "researched"' (Ateljevic, et al., 2005, p. 10). As a technique, it is recommended that journaling begin prior to fieldwork so as to capture pre-field anxieties and expectations, as well as serve as a tool for reflexivity during the research process. However, it can be taken up at any point in the process and function to record fieldwork stress and facilitate self-care.

For author 1, journaling involved noting down the feelings of guilt, intense empathy, shock, 
confusion, and isolation described in the experiences above. Journaling can also include epistemological concerns about research biases and anticipated implications of collecting, transcribing, and coding the data. In this study, the journal entries of author 1 addressed concerns about the emotional work involved in doing the research, including the feelings and experiences associated with the anxieties that were produced because of interaction with the host community and tourists; shocks, surprises, and unexpected responses during fieldwork and maintaining a record of incidents that author 1 found alienating (culturally, psychologically, socially) or demoralizing.

For dark tourism research, and likely tourism research more broadly, journaling is key to reflexive practices that continually interrogate researcher perceptions and interactions with tourists. For example, dark tourism researchers may often find themselves observing tourists whose behavior at sites of death, tragedy, disaster, and conflict are triggers for researchers who perceive them as improper and insensitive. Although it is advisable for researchers to maintain a distance between themselves and the research participants as a way of protecting their psychological well-being; there may be unexpected situations at the field-site that are likely to affect the researcher's perception of mortality and ethics. Examples of such situations are falling sick during fieldwork and respondents crying regularly during interviews. In these situations, journaling is an effective way to keep a track of the faltering emotions, anger, misjudgments, and experiences over a period of time as it serves as a platform for daily reflection and an emotional outlet for the researcher. This also helps the researcher reflect on the biases that that accompany personal judgement and could influence post-fieldwork analyses. Thus, journaling in conjunction 
fieldnotes is evidence of reflexivity and self-care in practice.

\section{Peer debriefing}

Regular meetings (weekly, (bi-)monthly, etc) with colleagues, supervisors, and/or friends to debrief on research experiences can serve important self-care needs. Debriefing is used to assist researchers in dealing "with their own reactions to the intense emotions expressed by subjects" and witnessed in the research process (Pickett, et al., 1994, p.250; Rager, 2005). In retrospect, we can see that this strategy would have been particularly useful to addressing issues of positionality - insider/outsider roles - that brought about challenges related to class, gender, and sociocultural belonging in Varanasi.

Moreover, peer debriefing can be a productive co-constructive strategy in which groups of peers meet to support one another (in person or via telecommunications media) as listeners to each other's debriefings. Peer debriefing is not only useful in terms of providing a fresh, renewed perspective of data collection and the research questions but also serving as a source of temporary rejuvenation and preventing the researcher from feeling demoralized. Further, one benefit of pervasive social media is that online support groups can also be utilized as a means of peer debriefing. As such, this practice can also begin prior to fieldwork and continue throughout the process, or be taken up at any point necessary. However, peer debriefing might be difficult for those researchers who work in remote locations having intermittent connectivity (phone or internet). 


\section{Counseling}

When more specific and specialized communication is required, counseling or therapy sessions can be beneficial. Most universities provide health services that can be accessed by staff and students, which often include counseling for a reasonable price. Rager's (2005) account of emotional turmoil in interviewing cancer patients describes the help personal counseling provided to her in moments of overwhelming fear and anxiety. Similarly, Author 1 took advantage of university counseling services to attend to the lingering emotional pain and anxieties of being immersed in a space of death, funerary rites, and grieving. However, this selfcare strategy was put into place only after fieldwork had been completed. As an active means of attending to author 1's emotional and psychological health, it would have been beneficial to seek out such care services (even if only through telecommunications media) while still in the field. Therefore, it is important that researchers to be aware of psychological health services available at their research institutes or elsewhere before they embark on their fieldwork.

\section{Time-out}

While the above strategies can be introduced as needed to cope with emotional stress of fieldwork experiences as the research process is on-going, there may be moments when time away and spatial distance from the source of stress are required (see Newell \& MacNeil, 2010). As Author 1 describes above, when the daily experiences of Varanasi's cremation grounds resulted in personal preoccupations, anxieties, and sleep disturbances, temporary time-out from the field was crucial and allowed for reflection that was not possible while focused on data collection. It demonstrates the kind of active, autonomous action for the sake of one's health that 
researchers must be prepared to take. This temporary detachment had a therapeutic effect and regenerative capacity. It also served as an important stage in engaging reflexivity as a methodology, as the decision to take a fieldwork "time-out" was difficult, as it brought with it feelings of self-doubt, new anxieties, and even shame, which needed to be attended to personally but also through researcher-as-instrument inquiry (Pezalla, et al., 2012) as to the effect of author 1's experiences on her participants and knowledge construction.

\section{Member checking}

Also referred to as "participant verification", member checking is an unexpected self-care strategy, which Rager (2005) points out, offers closure in situations where the researcher maintains an emotional connection, particularly in terms of concern, for research participants. In asking interviewees to review transcripts for accuracy, the researcher is able to check-in with them under circumstances that are less intense. For dark tourism research, member checking can include tourists who were interview participants and shared personal stories of pain and grief, tour guides who regularly recite stories of tragedy and violence, members of local communities who live amongst destruction (from conflict or disaster), just to name a few. Thus, as a self-care strategy member checking serves as an active engagement with factors that effect one's emotional health, such as worry for those met in the field.

\section{Mindfulness techniques}

As a broad category of self-care practice, mindfulness techniques allow the researcher the mental space to step away from the research context, even if physical distance cannot be obtained 
(Rager, 2005). These can include physical exercise, meditation, spiritual practice, and recreation/leisure activities. While these activities do not pertain directly to coping with the source of emotional stress, they are important for self-care inasmuch as they foreground the researcher's personal preferences for the use of leisure time (see Newell and MacNeil, 2010). As such, they demonstrate active, autonomous participation in one's physical and emotional health.

While Author 1 employed only some of these strategies, in analyzing her experiences and researching reflexivity exercises and self-care practices it quickly became apparent that had she been previously familiar with such tools she would have likely benefited from their use to boost her resilience in the field. Furthermore, familiarity and understanding of the role of these strategies would have also offered emotional support and reassurance that what she was experiencing, while not foreseen, was manageable and not necessarily unusual. In fact, when a counselor provided her with familiar therapeutic practices, her response was self-reflexive: "Why didn't I know about this earlier?” As such, self-care strategies with a focus on reflexivity exercises must be further integrated into our research processes, particularly for our students who must learn not only data collection techniques but also the significance of using self-care practices to maintain one's physical and emotional health throughout fieldwork.

\section{Conclusion}

Through this reflexive account of fieldwork at Varanasi, we present some potential challenges, 
practical considerations, and emotional consequences of dark tourism research. The need to recognize the emotional process of research and embracing the personal dimensions of fieldwork within qualitative research, in general, is not a new conclusion (see Kleinman \& Copp, 1993; Ateljevic, et al., 2005; Feighery, 2006; Rager, 2005; Arber, 2006; DeLuca \& Maddox, 2015). Active engagement with one's feelings is central for research on sensitive topics, such as death, because just like our participants researchers are also often affected by the sensitive content and emotionally charged spaces of dark tourism. We cannot always control our emotions and, in fact, doing so can sometimes also cause longer term emotional harm. In attending to the potential emotionality of dark tourism spaces and dark tourists, we must also attend to the researcher's emotional needs. By focusing on the challenges of positionality, role negotiation, gender dynamics, and (reverse) cultural shock experienced by Author 1, we have identified a number of reflexivity activities and self-care strategies that can be put into practice so as to attend to the researcher throughout the research process. Of course, this is not an exhaustive list, as each individual might also identify strategies that fit their personal needs. Nevertheless, these strategies deserve greater attention in our methodology courses, along with practicum cases (see Newell \& MacNeil, 2010), and pre-fieldwork compliance measures at research institutions to prepare our students for a wide range of potential unforeseen challenges. We would argue that even the seasoned researcher would find these strategies useful. And while we have focused on dark tourism, we do not wish to limit the benefit of reflexivity and the need for researcher selfcare to this sub-field alone. Death tourism at Varanasi has been but a case through which to demonstrate a need. These strategies would also be quite useful in other areas of tourism-related work in which the researcher find her/himself engaged with emotionally sensitive and potentially 
traumatic sites.

Author 1's emotional involvement in Varanasi continued even after the completion of her fieldwork, which inspired her seeking further reflexivity exercises and coping strategies. In discovering the importance of self-care, she also came to better understand the ways her experiences could be put to use in the analysis of the data collected. Not only is she now able to more carefully listen, rather than attempt to push aside her own emotionality, but she is also better able to use her empathy to take notice of subtle cues in the interview recordings. Further, exploring her positionality has also shed light on the nuanced layers of the various ways interviewees feel about death and this has boosted her curiosity towards understanding their disparate worldviews. Together, this deeper engagement with the research process has also uncovered previously unnoticed ethical dimensions of dark tourism research. In conclusion, emotional well-being matters in relation to both the researched and the researcher pursuing rigorous and credible qualitative research.

\section{References}

Arber, A. (2006) Reflexivity: A challenge for the researcher as practitioner? Journal of Research in Nursing, 11(2), 147-157.

Ashworth, G.J. (2002). Holocaust tourism: The experience of Kraków-Kazimierz, Journal 
International Research in Geographical and Environmental Education, 11(4), 363-367.

Ateljevic, I., Harris, C., Wilson, E., \& Collons, F. E. (2005). Getting 'entangled': Reflexivity and the 'critical turn' in tourism studies. Tourism Recreation Research, 30(2), 9-21.

Baszanger, I. and N. Dodier (1997) Ethnography relating parts to the whole. In Silvermann, D. (ed.) Qualitative Research. (Pp. 8-23). London: Sage.

Behar, R. (1996). The vulnerable observer: Anthropology that breaks your heart. Boston, MA: Beacon Press.

Blackman, S.J. (2007). 'Hidden ethnography': Crossing emotional borders in qualitative accounts of young people's lives. Sociology, 41(4), 699-716.

Bourdieu, P. (1977). Outline of a theory of practice. Cambridge: Cambridge University Press.

Buda, D. (2015). Affective tourism: Dark routes in conflict. Routledge, Taylor and Francis group.

Buda, D., d'Hauteserre, A-M., \& Johnston, L. (2014). Feeling and tourism studies. Annals of Tourism Research, 46(1), 102-114

Burkitt, I. (1997). Social relationships and emotions. Sociology, 31(1), 37-55. 
Carter, K. \& Delamont S. (1996). 'Introduction'. In Carter, K. \& Delamont, S. Qualitative research: The emotional dimension. Aldershot, Brookfield: Avebury.

Coffey, A. (1999). The Ethnographic Self: Fieldwork and the Representation of Identity. (pp ixxv). London: Sage

Dean, K. (1989). Conceptual, theoretical and methodological issues in self-care research. Soc. Sci. Med, 29(2), 117-123.

DeLuca, J. R. \& Maddox, C. B. (2015) Tales from the ethnographic field: Navigating feelings of guilt and privilege in the research process. Field Methods, 28(3), 284-299.

Denzin, N. (1984). On Understanding Emotion. San Francisco: Jossey-Bass

Dewalt, K. M., \& Dewalt, B. R. (2002). Participant observation: A guide for fieldworkers. New York: Altamira Press.

Dickson-Swift, V.; James, E.; Kippen, S. and Liamputtong Rice, P. (2007), 'Doing sensitive research: What challenges to qualitative researchers face?', Qualitative Research, 7(3), 327-353.

Domosh, M. (1998). Geography and gender: Home, again? Progress in Human Geography 22(2), 276-82. 
Eck, D. L. (1983). Banaras, city of light. Princeton University Press

Ellis, C. (1991). Emotional sociology. In Studies in symbolic interaction, N. Denzin (Ed.) (pp. 123-45). Greenwich, CT. JAI.

England, K. (1994). Getting personal: Reflexivity, positionality and feminist Research. Professional Geographer. 46(1), 80-89.

Feighery, W. (2006). Reflexivity and tourism research: Telling an(other) story. Current Issues in Tourism, 9(3), 269-282

Freire, P. (2000). Pedagogy of the oppressed (30 ${ }^{\text {th }}$ anniversary ed.). New York, NY: Continuum

Fries-Britt, S. L., \& Turner, B. (2001). Facing stereotypes: A case study of Black students on a White campus. Journal of College Student Development, 42(5), 420-429.

Ganga, Deianira \& Scott, Sam (2006). Cultural "insiders" and the issue of positionality in qualitative migration research: Moving "across" and moving "along" researcher-participant divides. Forum Qualitative Sozialforschung / Forum: Qualitative Social Research, 7(3), Art. 7

Gilbert, K. (2001), Introduction: Why are we interested in emotions? In The emotional nature of 
qualitative research, K. Gilbert. (Ed.) (pp.3-14) Florida: CRC Press LCD.

Goleman, D. (1995) Emotional intelligence. New York: Bantam Books.

Gullahorn, J.T., \& Gullahorn. J.E. (1963). An Extension of the U*curve Hypothesis. Journal of Social Issues, 14(1), 33-47.

Hochschild, A. (1983). The managed heart: The commercialization of human feeling. Berkeley, CA: University of California Press.

Hockey, J. (1996). Putting down smoke: Emotion and engagement in participant observation. In: Carter, K., Delamont, S. (Eds.), Qualitative Research: The Emotional Dimension. (pp. 12-27), Avebury, Aldershot.

Holland, J. (2007). Emotions and research, International Journal of Social Research Methodology, 10(3), 195-209.

Hubbard, G.; Backett-Milburn, K. and Kemmer, D. (2001).Working with emotion: issues for the researcher in fieldwork and teamwork, International Journal of Social Research Methodology, 4 (2,) $119-137$.

Jaggar, A. M. (1989). Love and knowledge: Emotion in feminist epistemology. In A. M. Jaggar 
\& S. R. Bordo (Eds.), Gender/body/knowledge: Feminist reconstructions of being and knowing (pp. 145-171). New Brunswick, NJ: Rutgers University Press

Johnson, B. and Macleod Clarke, J. (2003). 'Collecting sensitive data: the impact on researchers', Qualitative Health Research, 13(3), 421-434.

Kezar, A. (2002). Reconstructing static images of leadership: An application of positionality theory. Journal of Leadership Studies, 8(3), 94-109.

Killian, K. D. (2008) Helping till it hurts? A multimethod study of compassion fatigue, burnout, and self-care in clinicians working with trauma survivors. Traumatology, 14(2), 32-44.

Kleinman, S. and Copp, M.A. (1993). Emotions and Fieldwork. Thousand Oaks, CA: Sage.

Lee-Treweek, G, (2000). The insight of emotional danger: Research experience in a home for elderly people, Stephanie (Eds.), Danger in the Field: Risk and Ethics in Social Research. (pp 114-131.) Routledge, London.

Maynard, M. and Purvis, J. (1994) 'Introduction: Doing feminist research' in M. Maynard and J. Purvis (editors) Researching Women's Lives from a Feminist Perspective. London: Taylor and Francis. 
Merriam, S. B., Johnson-Bailey, J., Lee, M. Y., Lee, Y., Ntseane, G., \& Muhamed, M. (2001).

Power and positionality: Negotiating insider/outsider status within and across cultures.

International Journal of Lifelong Education, 20 (5), 405-416.

Moser, S. (2008).Personality: A New Positionality? Area, 40 (3): 383-392.

Newell, J. M., \& MacNeil, G. A. (2010). Professional burnout, vicarious trauma, secondary traumatic stress, and compassion fatigue: A review of theoretical terms, risk factors, and preventive methods for clinicians and researchers. Best Practices in Mental Health, 6(2), 57-68.

Oakley A (1981). Interviewing women: a contradiction in terms, In Roberts, H. (ed) Doing feminist research, (pp. 3-62), Routledge \& Kegan Paul, London.

Oberg, K. (1960). Culture shock: adjustment to new cultural environments. Practical Anthropology 7(2), 177-182.

Parry, J. (1994). Death in Banaras. Cambridge University Press

Pellatt, G. (2003). Ethnography and reflexivity: emotions and feelings in fieldwork Nurse Researcher, 10(3), 28-37.

Pezalla, A. E., Pettigrew, J., \& Miller-Day, M. (2012). Researching the researcher-as-instrument: 
an exercise in interviewer self-reflexivity. Qualitative Research : $Q R, 12(2), 165-185$.

Pickett, M., Walsh Brennan, A. M., Greenberg, H. S., Licht, L. \& Worrell, J. D. (1994) Use of debriefing techniques to prevent compassion fatigue in research teams. Methodology Corner, $43(4), 250-252$.

Rager, K. B. (2005) Self-care and the qualitative researcher: When collecting data can break your heart. Educational Researcher 34(4), 23-27.

Rosenberg, (1990). Reflexivity and emotions. Social psychology quarterly, 53(1), 3-12.

Rabinow, P., (1977), Reflections on fieldwork in Morocco. Berkeley: University of California Press

Rowling, L. (1999). Being in, being out, being with: affect and the role of the qualitative researcher in loss and grief research, Mortality, 4(2), 167-181.

Stewart, L., \& Legatt, P.A. (1998). Culture shock and travelers. Journal of Travel Medicine, 5 $(1), 84-88$.

Sword, W. (1999). Accounting for the presence of self: Reflections on doing qualitative research, Qualitative Health Research, 9(2), 270-278. 
Thurnell-Read, T. (2011). “Common-sense' research: Senses, emotions and embodiment in researching stag tourism in Eastern Europe'. Methodological Innovations Online. 6(3), 39-49.

Wax, R. H. (1979). Gender and age in fieldwork and fieldwork education: No good training is done by any man alone. Social Problems, 26(4), 509-523.

Wharton, A.S. (1999). 'The psychosocial consequences of emotional labor', Annals of the American Academy of Political and Social Science, 561: 158-76.

Widdowfield, R. (2000).“The Place of Emotions in Academic Research.” Area 32(2), 199-208.

Williamson, H., (1996). Systematic or sentimental? The place of feelings in social research. In Qualitative Research: The Emotional Dimension. Carter, K., Delamont, S. (Eds.), (pp. 28-41), Avebury, Aldershot,

Wolf D. (1996). Situating feminist dilemmas in fieldwork. In Feminist dilemmas in fieldwork, D Wolf (Ed.), (pp. 1-55) Boulder, Colo.: Westview Press.

Young, E. \& R. Lee. (1996). Fieldwork feelings as data: 'emotion work' and 'feeling rules' in first person accounts of sociological fieldwork. In Health and the sociology of the emotions, V. James and J. Gabe (Eds.), (pp. 97-113). Oxford: Blackwell Publishers. 
